\title{
Reacciones a la independencia de Cuba: el caso de la prensa sevillana *
}

\author{
Rosario Sevilla Soler \\ Escuela de Estudios Hispano-Americanos. Sevilla \\ Consejo Superior de Investigaciones Científicas
}

Este trabajo pretende analizar la independencia cubana pero no tal y cómo se produjo en realidad, sus causas o consecuencias -algo que ya ha sido repetidamente estudiado por la historiografía internacional-, sino como se vio aquel proceso histórico desde Andalucía, y concretamente desde Sevilla.

Se parte del examen de la prensa de la época -y concretamente de cuatro periódicos diarios: El Noticiero Sevillano, El Porvenir, El Progreso y El Baluarte- para tratar de determinar cómo se hicieron eco del problema colonial y su desenlace. En definitiva, se trata de analizar la guerra contra los cubanos, la intervención norteamericana en el conflicto y la Paz de París no como sucedieron, sino como las publicaciones periódicas las transmitieron a sus lectores; en resumen, la visión que la sociedad andaluza tuvo de los sucesos que desembocaron en la pérdida de las últimas colonias españolas en América, y las distintas reacciones de la prensa en función de la ideología de cada uno de los diarios examinados.

De todos es conocido el impacto que la pérdida de las últimas colonias españolas en América en 1898 produjo entre los intelectuales y la clase política españolas; pero lo es menos el que tuvo entre la población en general. El interés por ello me llevó hace tiempo a iniciar un estudio sobre la crisis del 98 en la conciencia andaluza, para el que resultaba esencial el análisis de la prensa periódica. Por una parte, lo es por cuanto en ella se reflejan las distintas opiniones de cada sector ideológico de la sociedad andaluza sobre el problema. Por la otra, es exponente también de la versión que de los sucesos que condujeron al fin del imperio español recibió el ciudadano de a pie, cuyo único medio para estar al tanto de lo que estaba ocurriendo al otro lado del mar era esa prensa. Por eso, este trabajo no pretende analizar la independencia cubana, algo que ya se ha hecho repetidamente, sino ver cómo los periódicos se hicieron eco de ese problema histórico, con sus aciertos y falsedades.

* Este trabajo forma parte del Proyecto Los Orígenes de la Crisis: Grupos de Poder y Estado Oligárquico en América Latina (AME 90-0849-C02-02), financiado por la CICYT a través del PNI. 


\section{La autonomía y la prensa}

Las peticiones criollas de un estatuto de autonomía para Cuba habían sido desoídas repetidamente por el gobierno y las Cortes españolas. Los líderes de los partidos peninsulares se mantenían divididos en esta cuestión; mientras Maura, ministro de Ultramar con Sagasta, se mostraba totalmente partidario de la autonomía, criterio que compartía con el conservador Silvela y, en parte, con Cánovas, para Romero Robledo y los suyos la concesión de la autonomía era algo vergonzoso para el país, y que, además, entregaría la isla a los separatistas. Por otro lado, los unionistas cubanos supieron ejercer la suficiente presión como para que el legislativo repudiara semejante medida. '

$Y$ aunque finalmente la sensatez se impuso, era ya demasiado tarde. El 13 de febrero de 1895 se aprobaba la base primera de una ley autonómica para Cuba; pero 4 días más tarde el grito de Baire iniciaba la segunda guerra de independencia cubana. Las reformas, escasas y tardías, no sólo no lograron frenar el separatismo sino que, por el contrario, hicieron temer a los independentistas que la población podría llegar a contentarse con ellas, con lo que, en definitiva, no hicieron sino acelerar el proceso. Y aunque, en teoría, la situación no resultaba favorable a los insurrectos, la realidad mostraría muy pronto que España no podía ganar la guerra. ${ }^{2}$

La mayor parte de los grupos políticos y de la prensa consideraron inevitable esa contienda; pero no dudaron en ningún momento del triunfo de España en ella, en virtud de su superioridad militar sobre los insurrectos. Las únicas y escasas protestas y muestras de desconfianza al respecto vinieron de algunos republicanos y grupos obreros. En este sentido es significativa la actitud de Pi y Margall —del partido Federal- y otros destacados republicanos, que ya en 1895 se manifestaban en contra de aquélla, por considerarla una sangría - económica y humanainútil para el país. Los discursos del líder republicano, reflejados por la prensa de la época, eran contundentes en este sentido; una y otra vez exigía el fin de una guerra que, en contra del sentir general, sostenía que no podía ganar la metrópoli. Dado que el triunfo militar en Cuba era, a

1 Ver sobre ello Carr, R.: España, 1808-1939. Barcelona, 1970, págs. 365 a 368.

2 Palacio Atard, V.: La España del Siglo XIX. 1808-1898. Madrid, 1978, pág. 512. Ver también Forner, Ph. S.: La Guerra Hispano-Cubana-Norteamericana y el Nacimiento del Imperialismo Norteamericano. 1895-1898. Madrid, 1975. Vol. I, pág. 51. 
su juicio, imposible, parecía fuera de lugar que se continuara luchando y murieran más jóvenes cuando a lo máximo que se podía aspirar era a un pacto como el que se había firmado en $1878 .{ }^{3}$

La realidad mostró que el líder republicano tenía razón; la situación de España se fue haciendo poco a poco insostenible, y en 1897 el gobierno se vio forzado a dictar nuevas reformas legislativas en favor de la autonomía. Estas reformas implicaban la existencia de un gobierno autonómico y una Cámara de Representantes para Cuba; todo el poder - salvo en lo referente a política internacional y defensa- quedaba en la isla. ${ }^{4}$

Ese nuevo avance en la autonomía fue visto de manera muy diferente por la prensa española, que atacó o ensalzó exageradamente el sistema según la posición política de cada periódico; pero no ocurrió lo mismo en la prensa sevillana, en la que - siendo en todo momento cauta en cuanto a los resultados finales y sin dejarse llevar por el optimismo- hay una extraña unanimidad a la hora de dar un margen de confianza al régimen autonómico.

Así, El Noticiero Sevillano -que se define como "diario independiente"- escribía el 12 de enero de 1898 un editorial con el título de "Entre todos la mataron", en el que criticaba la reacción de los periódicos importantes ante la autonomía. Y, concretamente, la "deplorable campaña" de la gran prensa de la que una parte exagera "las excelencias del nuevo régimen colonial, mientras otra refuerza los ataques contra el mismo" según su cercanía u oposición al gobierno. Afirmaba el citado editorial, que ese enfrentamiento que tenía lugar en la prensa, esa carrera por ver quien sacaba más trapos sucios, no lograría sino hacer fracasar la autonomía cubana; hacer fracasar, en definitiva, "lo que pide el pueblo, lo que suplican las madres cuyos hijos agonizan en Cuba, lo que exige nuestro tesoro exhausto...". 5

Y El Porvenir - que se autodenominaba "diario de avisos y noticias", sin aparentar una ideología clara- era prácticamente de la misma opinión. Al comenzar el nuevo año se felicitaba por lo que parecía ser

3 Ver sobre ello la prensa periódica de aquellos días, además de los discursos pronunciados en 1895 y 1896 por Pi y Margall, en Conangla Fontanilles, J: Cuba y Pi y Margall. La Habana, 1947.

4 García Nieto, M. C. y otros autores: La Restauración y el Desastre. 1874-1898. Madrid, 1972, pág. 21, y Palacio Atard, V.: La España del...., pág. 558.

5 El Noticiero Sevillano, 12 de enero de 1898. 
realmente una nueva época para los conflictos coloniales, ansioso porque se terminara con "las criminales guerras" que estaban "arrancando lágrimas de muchos ojos y llevando el luto a centenares de familias". 6

Por su parte El Progreso, órgano de expresión del partido liberal en el poder, y aunque sólo fuera porque lo propugnaba el gobierno del liberal Sagasta, apoyaba claramente el sistema autonómico. Pero consideraba exagerado el optimismo que la autonomía despertaba en ciertos sectores, ya que "los intereses creados por la guerra" eran muchos; y pedía tranquilidad a las distintas fuerzas políticas para evitar el fracaso. ${ }^{7}$

Por último, El Baluarte, de ideología republicana -y en contra de lo que podría pensarse en principio dada su pertinaz y continua oposición al gobierno-, se mostraba totalmente partidario de la autonomía. Bajo su punto de vista se trataba de "una justa concesión" a los cubanos, a la que se debía haber llegado mucho antes. $Y$ en este caso sus mayores ataques, por tanto, no estuvieron dirigidos al gobierno, sino a la campaña desatada en determinados sectores contra la autonomía; y concretamente hacia los representantes de la Unión Constitucional, a los que consideraba "antiguos expoliadores de Cuba", y a los que acusaba de llevar a cabo una campaña de difamación contra el nuevo régimen, exclusivamente por su temor a perder los privilegios de que habían gozado hasta entonces. ${ }^{8}$ Para este periódico la necesidad de solucionar los problemas coloniales era urgente. Las consecuencias de la guerra - desde la sangría de jóvenes a la crisis económica provocada por la disminución del tráfico comercial- se dejaban sentir con fuerza; y, a su juicio, la manera de solucionarlos era, en principio, la concesión de una autonomía como la que se implantaba. ${ }^{9}$

No obstante, el nuevo régimen nacía herido de muerte. Por una parte, y como afirmaban numerosos observadores de la vida política, la herida era vieja. ${ }^{10}$ No podemos olvidar que las peticiones criollas en ese sentido habían sido rechazadas una y otra vez por las Cortes españolas desde la primera guerra. Tras el Pacto de Zanjón de 1878 los criollos ricos, en su mayor parte autonomistas, presionaron aún con más fuerza ante el temor de un predominio de los independentistas; pero sus inten-

6 El Porvenir, 1 de enero de 1898.

7 El Progreso, 14 de enero de 1898.

8 El Baluarie, 12 de enero de 1898.

9 Ibidem, 18 de enero de 1898.

10 El Progreso, 14 de enero de 1898. 
tos chocaban no sólo con la oposición de los diputados españoles, sino - como ya se ha dicho- con la de los unionistas de Cuba, en conflicto claro con ellos por el poder local, y con gran influencia en la Península. Por la otra, los Estados Unidos no estaban dispuestos a consentir su triunfo. El primero de enero de 1898 comenzó a funcionar el nuevo gobierno autonómico en Cuba; y doce días después el presidente de los Estados Unidos afirmaba ya que dicho régimen había fracasado. "

$Y$ aunque estas declaraciones fueran resultado de los intereses norteamericanos en la zona, ${ }^{12}$ la realidad no hizo sino confirmar las palabras del presidente norteamericano. A finales del mismo mes de enero, El Baluarte acusaba de mentir - a sabiendas - a los periódicos que a diario hablaban sobre la paz en Cuba; como si ésta fuera un hecho consumado por el solo hecho de haberse constituido el gobierno autonómico, y como si los independentistas hubieran desaparecido del mapa; y se preguntaba desde sus páginas el propósito que se buscaba con ello. ${ }^{13}$ Aunque partidario de la autonomía, este diario consideraba que no bastaba con ella para terminar de la noche a la mañana con el problema cubano, cuyas raíces eran profundas. ${ }^{14}$

Y el mismo Progreso, a pesar de su apoyo a los liberales en el poder, no tenía más remedio que reconocer la imposibilidad de una paz inmediata en Cuba, por mucha autonomía que se hubiera concedido a la isla. Aunque defendía el camino autonómico marcado por ese gobierno como el único posible para que la situación fuera mejorando, y para llegar a la paz en un futuro más o menos próximo, era consciente de que ésta no sólo no sería inmediata, sino tampoco fácil. ${ }^{15}$

\section{Reacciones a la intervención norteamericana}

Efectivamente la paz costaría aún mucha sangre; sobre todo al complicarse la situación con la intervención norteamericana en el conflicto.

11 Palacio Atard, V: La España del.... pág. 558.

12 Ver sobre ello Sevilla Soler, Rosario: Las Antillas y la Independencia de la América Española, Sevilla, 1986, y "La Intervención Norteamericana en Cuba y la Opinión Pública Andaluza", en Anuario de Estudios Americanos, Vol. XLIII, págs. 469-516. Sevilla, 1986. Ver también Palacio Atard, V: La España del...., pág. 554.

13 El Baluarte, 26 de enero de 1898.

14 Ibidem, 3 de febrero de 1898, y Editorial sobre el cumplimiento del tercer aniversario del grito de Baire en el mismo diario de 26 del mismo mes y año.

15 El Progreso, 6 de febrero de 1898. 
Aunque esta cuestión ha sido repetidamente estudiada - yo misma he tratado el problema con anterioridad en un estudio sobre dicha intervención y la opinión pública andaluza-, no podemos dejar de hacer alusión a la misma; si bien parece evidente que la independencia cubana era inevitable, también lo es que la intromisión norteamericana precipitó considerablemente el desenlace. ${ }^{16}$

En principio, la amenaza de intervención estadounidense fue acogida con escepticismo por la mayor parte de la prensa, mientras el gobierno hacía caso omiso a tal posibilidad; parecía como si las amenazas norteamericanas no fueran con él. ${ }^{17}$ No obstante, el órgano de expresión de su partido daba muestras de ser consciente de la situación real, cuando - ante el renacimiento de la insurrección en Filipinas - señalaba que su dominio por las armas era imposible, y que sólo se podía acabar con ella con medidas políticas. Y, al mismo tiempo, y a causa de las bravatas que ante la actitud estadounidense comenzaban a aparecer en parte de la prensa periódica, llamaba a la tranquilidad y a la moderación, para que no se llegara realmente a una guerra que no convenía a nadie. ${ }^{18}$

En esta situación varias potencias europeas se ofrecieron como mediadoras entre España y los Estados Unidos; prometieron su apoyo a la primera frente a las pretensiones norteamericanas, siempre que fuera capaz de llegar a un armisticio con los rebeldes cubanos que dejara sin argumentos a los que, en los Estados Unidos, se mostraban partidarios de la intervención en la isla. El gobierno español accedió -aparentemente- a declarar ese armisticio unilateralmente. Pero en la práctica las cosas eran diferentes; la condición que puso para mantenerlo -que los rebeldes entregaran las armas en un plazo de cinco días-, resultaba imposible de materializarse en la situación que atravesaba la isla en aquellos momentos. ${ }^{19}$

No obstante, la reacción de la prensa contra el armisticio no se hizo esperar; mientras algunos consideraban la actitud del gobierno como de puro entreguismo, otros, deseosos de que el resultado final fuera la paz y que nada pudiera obstaculizarla, se mostraban menos exaltados; eso sí, pedían algo que parecía imposible en aquellos momentos para

16 Forner, Ph. S.: La Guerra Hispano-Cubana..., T.I, pág. 190.

17 Ver sobre ello El Baluarte de 9 y 10 de febrero y 15 de marzo de 1898.

18 El Progreso, 15 y 20 de marzo de 1898.

19 El Noticiero Sevillano, 9 de abril de 1898. 
cualquier observador imparcial: "una paz honrosa" en la que quedara a salvo el prestigio nacional. ${ }^{20}$

De todos modos, y a pesar de las críticas a lo que consideraban "impasibilidad" del gobierno español ante las amenazas norteamericanas, una parte importante de la prensa parece ver ya claramente la gravedad del problema; y es también consciente de la necesidad de plantearlo crudamente a la opinión pública, con el fin de no despertar vanas ilusiones que pudieran llevar los ánimos por el camino equivocado. El Noticiero Sevillano, en su crónica política de 13 de abril, afirmaba en este sentido que no parecía existir esperanza de paz que no fuera sobre la base de la pérdida de Cuba; y que, por lo tanto, "convendría que todos los españoles fueran pensando en ello. Conservarla por las armas: perderla porla superioridad de las enemigas". Este tipo de prensa, no enfrentada abiertamente al régimen como la republicana, no se manifestaba aún decididamente a favor o en contra de la guerra; pero como la autonomía no había logrado detener ni a los insurrectos ni a los Estados Unidos - como se le había dicho que sucedería-, sí se mostraba partidaria de informar al país, y plantearle la cuestión en sus dimensiones reales para que éste opinara. ${ }^{21}$

La prensa gubernamental, por el contrario, hacía los mayores esfuerzos para ocultar la realidad, y para hacer creer a la población que la situación no era tan mala; para ello se escudaba en el hecho de que el presidente norteamericano no respondía a las exigencias de los insurrectos, que pedían ser considerados como beligerantes y que se reconociera la independencia de la isla. ${ }^{22}$ Efectivamente esto era cierto; pero también lo era que si no lo hacía era porque su objetivo no consistía en que la isla lograra su independencia, sino, tal y como El Noticiero Sevillano afirmaba ya por aquellos días, la pura y simple anexión del territorio. ${ }^{23}$

Antes de llegar a la confrontación bélica ambos países mantenían una doble negociación; en la primera de ellas, la que se realizaba de manera oficial, los Estados Unidos justificaban su posible intervención en Cuba con supuestos motivos humanitarios: la situación de los concentrados cubanos; en la otra, que se producía bajo cuerda, exigían simplemen-

20 Ibidem. El mismo día el diario recogía fragmentos de las reacciones de la prensa de Madrid -El Imparcial, El Liberal, El Progreso y El País-, en este sentido.

21 Ibidem, 13 de abril de 1898.

22 El Progreso, 14 de abril de 1898.

23 El Noticiero Sevillano, 17 de abril de 1898. 
te la entrega de la isla por parte de España. Las pretensiones estadounidenses eran inaceptables para aquélla, y ellos lo sabían; sólo perseguían provocar el enfrentamiento, que resultaba inevitable, por muchas concesiones que hiciera España, al no estar dispuesta a llegar a la única oferta que los Estados Unidos consideraban digna de tener en cuenta: el abandono sin más de sus colonias. El 18 de abril el Congreso y el Senado norteamericanos acordaban presentar un ultimátum al gobierno español para que abandonara la isla, y el 25 el Congreso declaraba la guerra. ${ }^{24}$

$Y$ aunque hasta entonces una parte significativa de la prensa fuera contraria a aquélla - El Noticiero Sevillano señalaba poco antes que realmente sólo se trataba de una simple cuestión de honor, ya que en la práctica "Cuba ya no nos pertenece" económica y administrativamente- ${ }^{25}$ lo cierto es que la agresión extranjera consiguió unirla contra los "yankees", el enemigo común. Con la única excepción de $E l$ Baluarte-que ataca duramente a los "jaleadores de la guerra"-, la prensa sevillana de la época no hizo sino exaltar los ánimos "patrióticos" e incitarlos a la lucha, haciendo creer, además, al público, que los medios españoles eran muy superiores a la realidad. ${ }^{26}$

En este sentido, Pi y Margall afirmaba encontrarse lleno de "ira", al comprobar "como ciertos periódicos... empujaron a la nación y al gobierno a que no cedieran en la cuestión de Cuba y rompieran con los Estados Unidos", mintiendo descaradamente sobre los medios bélicos de ambos países. ${ }^{27}$ Y la población, influenciada por esa exaltación y por las constantes llamadas al orgullo nacional, se dejó llevar casi entusiasmada a la guerra. Sólo más tarde, al faltar las prometidas victorias, seguiría a los republicanos en sus protestas. ${ }^{28}$

Muy pronto, no obstante, la realidad se mostraría crudamente; el inmediato desastre de Cavite sirvió para que diarios como El Noticiero Sevillano, en principio contrario a los republicanos, se interrogaran sobre la conveniencia o no de seguir la guerra, así como sobre la necesidad de discutir abiertamente esta cuestión, sin miedo a mostrarse públicamente a favor de la paz; en aquellos momentos eran muchos los que no lo hacían por temor a ser considerados "enemigos de la patria". Este periódi-

24 Palacio Atard, V.: La Restauración y..., pág, 21.

25 El Noticiero Sevillano, 17 de abril de 1898.

26 Ibídem, 22 de abril de 1898, y El Baluarte, 23 y 26 del mismo mes y año.

27 Conangla Fontanilles, J.: Cuba y Pi..., pág. 465.

28 García Nieto, M. C., y otros autores: La Restauración y..., pág. 21. 
co llegaba, incluso, a hacerse eco de las ideas del partido Federal, y concretamente de Pi y Margall. El partido Federal era el único grupo político que planteaba la cuestión sin tapujos, porque le interesaba políticamente hacerlo así. Abogaba por la suspensión de las hostilidades, y por una inmediata negociación de la independencia cubana con los insurrectos; esa negociación permitiría tratar la paz con los Estados Unidos, antes de perder frente a ellos no sólo Cuba, sino también Puerto Rico y todo el archipiélago filipino. A esta opinión el citado diario enfrentaba la del ministro de la Guerra, que afirmaba que un ejército que ni siquiera había entrado en combate no podía pedir la paz; ante esta disyuntiva, el diario planteaba la interrogante al lector para que se inclinara hacia uno u otro campo, pero lanzándolo más hacia el de Pi y Margall. ${ }^{29}$

Aún iba más lejos pocos días después, al afirmar que el único político que se atrevía a hablar con claridad de la cuestión era el citado Pi y Margall; y con él se preguntaba si era o no hora de pedir la paz, en virtud de si resultaba o no posible hacer frente al nuevo enemigo; pero nadie en el ámbito gubernamental se mostraba dispuesto a responder. ${ }^{30}$ Sólo otra publicación periódica, El Baluarte, contestaba a esa pregunta; y lo hacía en el sentido de que era imposible ganar la contienda. ${ }^{31}$

\section{Los deseos de paz}

Y al conocerse el desastre de Cavite ese sentimiento se extendió. El desengaño cundió rápidamente entre la prensa, y el deseo de poner fin a la guerra parecía unánime. ${ }^{32}$ Prácticamente desde entonces sólo El Porvenir y El Progreso apoyaron la acción del gobierno. El primero de estos periódicos afirmaba que no era el momento de pedir responsabilidades y lanzar acusaciones sin ton ni son, sino de unirse frente al enemigo común; ${ }^{33}$ el segundo, por su parte, acusaba de inconscientes a aquellas pu-

29 El Noticiero Sevillano, 3 de mayo de 1898.

30 Ibídem. 9 de mayo de 1898. Ver también sobre ello El Baluarte de 10 del mismo mes $\mathrm{y}$ año.

31 El Baluarte, 17 de mayo de 1898.

32 El propio órgano de expresión del partido liberal en Sevilla afirmaba que gran parte del problema radicaba en que los españoles, salvo las clases populares que habían dado a sus hijos, no habían sentido la guerra y se evadían de manera irresponsable ante las dificultades del gobierno para hacer frente a los gastos de la misma. El Progreso, 9 de junio de 1898.

33 El Porvenir, 9 de junio de 1898. 
blicaciones que habían empujado al país hacia la guerra desde sus páginas, sin darse cuenta de que el enemigo a batir era superior, y que, precisamente en los momentos en que debía prevalecer la unidad, lanzaban todo género de censuras y recriminaciones por esa misma guerra. ${ }^{34}$

Pero la realidad era que ellos mismos parecían dudar de la actuación del gobierno y de la victoria, cuando afirmaban "que, si hay alguna posibilidad de triunfo para España, no debe hacerse la paz ahora; que si no existe esa posibilidad, cuanto antes se haga será menos desventajosa", preparando ya de este modo a sus lectores para el abandono de la isla de Cuba. ${ }^{35}$

No obstante, sería la pérdida de la escuadra de Cervera en Santiago de Cuba, ${ }^{36}$ lo que se convertiría en el argumento definitivo para que en las páginas de los periódicos cundiera el desánimo; algunos llegaban a pedir la paz en las condiciones que fuera, mientras la mayor parte de la población no parecía ni siquiera reaccionar ante el desastre. ${ }^{37}$ Sin embargo, tampoco la paz resultaría sencilla.

Ya antes de la derrota de Santiago España buscaba la paz; pero a los Estados Unidos no le interesaba la misma antes de lograr en las Antillas una victoria definitiva. E incluso después de ésta, la prensa sevillana informaba que la respuesta al intermediario del gobierno español -el embajador francés en Estados Unidos- no ofrecía duda alguna al respecto: no aceptarían una paz sobre bases diferentes al abandono de $\mathrm{Cu}$ ba, Puerto Rico, Filipinas y las Marianas, y el pago de una indemnización de guerra. ${ }^{38}$

Esas afirmaciones de la prensa comenzaron a confirmarse muy pronto; a finales del mes de julio, el jefe del gobierno español hizo público que la petición de paz por parte de España se había hecho una semana antes, sin que, hasta entonces, se hubiera recibido respuesta. A juicio de la prensa, esa falta de contestación obedecía al deseo de los Estados Unidos de ocupar antes Puerto Rico y todas las Filipinas, para conservar sus posesiones en ellas al llegar el armisticio. ${ }^{39}$ De hecho, el presidente estadounidense se había dado oficialmente por enterado de la notificación

34 El Progreso, 12 de junio de 1898.

35 Ibídem, 3 de julio de 1898.

36 El Progreso y El Porvenir de 7 de julio de 1898.

37 El Baluarte, 9 de julio de 1898.

38 El Porvenir, 13 de julio de 1898.

39 El Noticiero Sevillano, 30 de julio de 1898. 
del embajador francés cinco días antes. Pero como, efectivamente, no tenía la misma prisa que España, ${ }^{40}$ y sus exigencias no habían variado en relación a las que la prensa había filtrado a comienzos de aquel mismo mes, dilató la respuesta. Para la mayoría de los periódicos estas exigencias eran exageradas, ${ }^{41}$ pese a lo cual, la urgencia por llegar al armisticio parecía estar presente en la mente de todos. ${ }^{42}$

Nadie se ocupaba de la guerra si no era para hablar de paz, y el país parecía resignado a sufrir "todos los despojos que se dignen imponer los yankees". ${ }^{43}$ No obstante las críticas por lo duro de las demandas norteamericanas, desde los primeros días de agosto se esperaba con ansiedad el cese de las hostilidades, que finalmente llegaría el 12 de aquel mismo mes. ${ }^{44} \mathrm{El}$ Protocolo que se firmó al respecto ratificaba - tal y como venía anunciando la prensa-, la pura y simple aceptación de las pretensiones estadounidenses por parte de España, que renunciaba a la soberanía sobre Cuba y el resto de las islas en las Indias Occidentales, cediendo también a los vencedores una isla en las Marianas o "Ladrones". Los Estados Unidos ocuparían además Manila hasta la conclusión del tratado definitivo de paz. El abandono de las Antillas sería inmediato, y ambos países nombrarían una comisión de al menos cinco delegados, que discutirían en París el acuerdo definitivo. ${ }^{45}$

Las conversaciones de paz se iniciaron en la capital francesa sin las más mínimas esperanzas para España. De hecho, El Baluarte se preguntaba pocos días antes qué sentido tenía dar tantas vueltas como se estaba dando a las instrucciones que se iban a entregar a los comisionados de paz. Al carecer éstos del más mínimo margen de maniobra, no podían sino decir que sí a todas y cada una de las exigencias norteamericanas. ${ }^{46}$ Las primeras sesiones no hicieron sino confirmar la idea que la prensa ya había lanzado sobre lo que iba a ocurrir en ellas: que España debería pasar por las "horcas caudinas", ${ }^{47}$ y aceptar todo lo que los comisionados norteamericanos quisieran. No hubo discusiones, sino simple

40 El Porvenir, 31 de julio de 1898.

41 El Noticiero Sevillano, 1 de agosto de 1898.

42 El Porvenir, 2 de agosto de 1898.

43 El Baluarte, 5 de agosto de 1898.

44 Forner, Ph. S.: La Guerra Hispano..., T.II, pág. 43.

45 Rodríguez Martín, J.: Los Desastres y la Regeneración de España. Relatos e Impresiones. La Coruña, 1899, pág. 131.

46 El Baluarte, 23 de septiembre de 1898.

47 Ibídem, 4 de noviembre de 1898. Ver también El Noticiero Sevillano del mismo día. 
"acatamiento" de los requerimientos estadounidenses. ${ }^{48}$ Los Estados Unidos tenían la fuerza y España "se hallaba indefensa y económicamente arruinada". ${ }^{49}$

Algunos consideraron que esto era inaceptable. El Porvenir reproducía el 5 de noviembre de 1898 un artículo sin firma aparecido en $E l$ Correo Español, en el que se proponía la ruptura de las negociaciones y la reanudación de la lucha, antes que someterse a tal indignidad; ${ }^{50}$ otros proponían abandonar las conversaciones - aunque sin volver a la lucha-, y que los norteamericanos se apoderaran sin más de todo; eso sí, sin la firma de España, que implicaría una clara humillación. ${ }^{51}$ Pero, fuera cual fuera su posición sobre esta cuestión, unos y otros hablaban de "despojo" y "liquidación infame". 52

\section{Conclusiones}

En resumen, la reacción de la prensa sevillana ante los hechos que llevaron a la crisis del 98 fue unánime en cuanto a la necesidad de la autonomía. Desde El Porvenir al Progreso, pasando por El Baluarte, opositor acérrimo al régimen, todos se mostraban de acuerdo en dar un margen de confianza al sistema autonómico. Esa unanimidad se rompió en un principio en relación a la guerra, en virtud de la ideología política predominante en cada uno de los periódicos, en función de su cercanía u oposición no sólo al gobierno, sino al sistema político de la restauración. Y, como muestra de ello, sólo hay que ver el claro enfrentamiento que existe entre las páginas de El Progreso y El Baluarte en esa etapa del proceso.

Por último, y a medida que van dándose cuenta de la realidad, los criterios se van unificando de nuevo para llegar a la paz prácticamente de acuerdo. Con la excepción del artículo de El Correo Español ya senalado, y que aunque recogido por la prensa sevillana no pertenecía a la misma, todos eran conscientes de que no había nada que hacer. El pue-

48 Palacio Atard, V.: La España del....., pág. 568.

49 Forner, Ph. S.: La Guerra Hispano...., T. II, págs. 85-86.

50 El Porvenir, 5 de noviembre de 1898.

51 El Baluarte, 23 de noviembre de 1898.

52 El Progreso de 6 de noviembre de 1898, y El Noticiero Sevillano de 13 del mismo mes $\mathrm{y}$ año. 
blo, a pesar de las fuertes discusiones que se producían diariamente en la prensa al respecto, parecía permanecer indiferente. Es más, la pérdida de las colonias no produjo ningún "sacudimiento de ira; más bien al contrario, el país ha hecho un gesto de filosófica conformidad, como a quien quitan de encima una carga molesta". ${ }^{53}$ Esto ocurrió ya desde la firma del armisticio, y se acentuó en el trascurso de las negociaciones de París. Sólo la prensa, las clases privilegiadas, los políticos y los intelectuales siguieron discutiendo la cuestión. El pueblo quería la paz al coste territorial que fuera y pasando por las humillaciones que resultaran necesarias. Y, poco a poco, la prensa no tuvo más remedio que hacerse eco también de ese deseo.

El Progreso, apoyando la postura del partido liberal, fue el primero en señalar la necesidad de olvidarse de una vez de aventuras exteriores para cuidar la riqueza interna. ${ }^{54} \mathrm{Y}$ su postura fue seguida por los demás; una vez que tuvieron clara la imposibilidad de mejorar los resultados de las conversaciones, lo único que proponían - haciéndose eco de la opinión pública - era que se llegara cuanto antes a la paz, acabando con la incertidumbre de aquellos días. ${ }^{55}$

La paz se firmó por fin el 10 de diciembre, y la trasmisión de poderes tuvo lugar en La Habana el primero de enero de 1899, 56 aunque eso, como todos sabemos, no representó la independencia de las antiguas colonias españolas. Los Estados Unidos habían comenzado su política expansionista y establecían su protectorado sobre las antiguas posesiones españolas, iniciando un "dominio" que, en el caso de Puerto Rico, dura hasta hoy.

53 El Progreso, 21 de agosto de 1898.

54 Ibídem, 15 de octubre de 1898.

55 El Noticiero Sevillano de 13 y 27 de noviembre de 1898, y El Porvenir de 16 del mismo mes y año. pág. 568 .

56 Forner, Ph. S.: La Guerra Hispano..., T.II, pág. 91 y Palacio Atard, V.: La España de..., 